\title{
Psychoanalysis: Science or Fiction?
}

\author{
Emanuel E. Garcia \\ University of Pennsylvania (Fourth-year medical student)
}

Follow this and additional works at: https://jdc.jefferson.edu/jeffjpsychiatry

Part of the Psychiatry Commons

Let us know how access to this document benefits you

\section{Recommended Citation}

Garcia, Emanuel E. (1986) "Psychoanalysis: Science or Fiction?," Jefferson Journal of Psychiatry. Vol. 4 : Iss. 1 , Article 4.

DOI: https://doi.org/10.29046/JJP.004.1.001

Available at: https://jdc.jefferson.edu/jeffjpsychiatry/vol4/iss $1 / 4$

This Article is brought to you for free and open access by the Jefferson Digital Commons. The Jefferson Digital Commons is a service of Thomas Jefferson University's Center for Teaching and Learning (CTL). The Commons is a showcase for Jefferson books and journals, peer-reviewed scholarly publications, unique historical collections from the University archives, and teaching tools. The Jefferson Digital Commons allows researchers and interested readers anywhere in the world to learn about and keep up to date with Jefferson scholarship. This article has been accepted for inclusion in Jefferson Journal of Psychiatry by an authorized administrator of the Jefferson Digital Commons. For more information, please contact: JeffersonDigitalCommons@jefferson.edu. 


\title{
Psychoanalysis: Science or Fiction?
}

\author{
Emanuel E. Garcia
}

The completion of this paper comes coincidentally at a time when a book by a scholarly philosopher, Adolf Grunbaum, entitled The Foundations of Psychoanalysis: A Philosophical Critique, has just been published and purports to answer the question of the scientific status of analysis. This temporally follows Jeffrey Masson's work (1) which accuses Freud of abandoning the so-called seduction hypothesis and by so doing laying unsound groundwork for the "science" that consumes Freud's nearly limitless energies. In short, it is a period in which psychoanalysis finds itself condemned, but perhaps in a more vehement and visible fashion than usual.

To be sure, psychoanalysis has always had to bear the brunt of vociferous hostility, which incidentally did not trouble Freud, given his understanding of the nature of the resistance to the revelations of analysis. Since those heady days in the early 1950's when analysis enjoyed an unequalled popularity, particularly in America, a rather shocking phenomenon has arisen. It seems that a fair number of analysts nowadays, in contradiction to Freud's most earnestly held belief, have relinquished the claim that psychoanalysis is a science. If this is true, if analysis indeed has no scientific base or methodology, very little remains to warrant serious consideration. At best it becomes merely one of the many forms of psychotherapy, useful for a rather limited range of the mental disorders and accessible to a very small percentage of the population, i.e., those who have the resources and willingness to engage in the laborious and often painful process of confronting the extraordinarily powerful and nearly intractable forces of the unconscious. If psychoanalysis is nothing more than this, if the therapy, as Freud feared, destroys the science, then it remains but an admirable oddity even to the most forgiving and optimistic of its enthusiasts. In this perspective the following comments by the narrator of Marie Cardinal's The Words to Say It are fully justified:

Freud was the puppeteer! They were his thick strings operating the little doctor. He was the priest of psychoanalysis, that religion in which a certain pompous, vainglorious and malevolent intellectual elite reveled (2).

There you have it: a religion, all powder and smoke, hocus-pocus, illusion, everything that Freud sought to avoid in his scrupulous undertaking. The

Emanuel Garcia is a fourth-year medical student at the University of Pennsylvania. He will enter a psychiatry residency in July. 
strength of Freud's conviction is evident from this revealing passage appearing in one of the New Introductory Lectures:

It is not permissible to declare that science is one field of human mental activity and that religion and philosophy are others, at least its equal in value, and that science has no business to interfere with the other two; that they all have an equal claim to be true and that everyone is at liberty to choose from which he will draw his convictions and in which he will place his belief. A view of this kind is regarded as particularly superior, tolerant, broad-minded and free from illiberal prejudices. Unfortunately it is not tenable. . It is simply a fact that the truth cannot be tolerant, that it admits of no compromises or limitations, that research regards every sphere of human activity as belonging to it and that it must be relentlessly critical if any other power tries to take over any part of it (3).

So much for Freud's opinion of illusion. But what does he really mean when he refers to psychoanalysis as a science, when he says "Psychoanalysis began as a method of therapy, but I did not want to commend it to your interest as a method of therapy but on account of the truths it contains, on account of the information it gives us about what concerns human beings most of all-their own nature" (4)?

First, as implied above, Freud gave no credence to what he termed the anarchistic view that there is no such thing as truth, no assured knowledge of the external world, that "What we give out as being scientific truth is only the product of our own needs as they are bound to find utterance under changing external conditions" (5). While acknowledging the intellectual appeal of such arguments (perhaps similar to that exerted by Xeno's paradoxes) he deftly notes their demise in the face of practical exigencies, as in the decision to administer one-tenth of a gram or ten grams of morphine to a patient.

Freud saw scientific pursuit as generally slow and laborious, likening progress in scientific work to that in analysis.

We bring expectations with us into the work, but they must be forcibly held back. By observation, now at one point, and now at another, we come upon something new; but to begin with the pieces do not fit together. We put forward conjectures, we construct hypotheses, which we withdraw if they are not confirmed, we need much patience and readiness for any eventuality, we renounce early convictions so as not to be led by them into overlooking unexpected factors. .In psychoanalysis, however, we have to do without the assistance offered to research by experiment (6).

This, by the way, the "puppeteer"!

Freud compared Science to a sculptor modeling clay (6), continually refining, revising, adding and subtracting until that criterion of truth- 
correspondence to the external world, or to follow the artist's metaphor, the "mirror up to nature"-is achieved. This metaphor, which links the two pillars of civilization, Science and Art, is characteristic of Freud, who often claimed that analysis merely systematized what great artists such as Shakespeare and Goethe had been providing us all along, namely, insights into human nature. "The only subject matter of psychoanalysis is the mental processes of human beings and it is only in humans that it can be studied" (7).

As to the position of psychoanalysis within the sciences, Freud had this to say:

Psychoanalysis is not a specialized branch of medicine . . but simply of psychology. It is certainly not the whole of psychology, but its substructure and perhaps even its entire foundation (8).

In response to the contemptuous criticism that psychoanalysis is impossible to consider seriously as a science, being an undertaking whose most general concepts are as lacking in precision as libido and instinct, Freud points out that:

This reproach rests on a complete misconception of the facts. Clear basic concepts and sharply drawn definitions are only possible in the mental sciences insofar as the latter seek to fit a region of facts into the frame of a logical system. In the natural sciences, of which psychology is one, such concepts are superfluous and indeed impossible. Zoology and botany did not start from correct and adequate definitions of an animal and a plant; to this very day biology has been unable to give any certain meaning to the concept of life. Physics itself, indeed, would never have made any advance if it had had to wait until its concepts of matter, force and gravitation, and so on, had reached the desirable degree of clarity and precision (9).

In summary, Freud firmly and unhesitatingly placed psychoanalysis amid the other sciences, sharing with them the pursuit of truth and the general weltanschauung. By creating hypotheses to fit the observed data, by continually being open to new data warranting a revision or even the wholesale demolition of such hypotheses, the investigation of the "mental processes of human beings," a wide and rich domain that includes every sphere of human activity would humbly proceed. That the conditions for conducting this investigation called for the practicing of the therapy is a distinguishing feature of psychoanalysis, but one that in no way diminishes its scientific status.

But let us pause to clarify our own ideas of what constitutes a scientific enterprise and what does not. Science, as etymologically implied, seeks to know; it seeks the truth about the world-including the inner nature of man-and attempts systematically to account for natural phenomena. For some sciences the task is made easier by the ability to isolate variables and run experiments. The task is less clear-cut for others, which often suffer the taint of being condemned as unscientific, probably owing to the fact that today most conceive 
of science as a pure realm of immutable facts, precise experiments and doubleblinded, randomized, placebo-controlled studies. This latter view is a gross misconception that deserves to be placed alongside those narrow attempts of sociologists and philosophers to establish firm criteria for scientificity that betoken very little understanding of their subject.

To return to the matter of whether psychoanalysis deserves to be called a science, I will draw heavily from a remarkably lucid paper by Robert Waelder (10). First, Waelder distinguishes various self-explanatory levels of the psychoanalytic process: observation; clinical interpretation; clinical generalization; clinical theory; metapsychology; and finally, Freud's philosophy. The last two are regarded as being far less important than the others. Of the metapsychological hypotheses, Freud himself said that they "are not the bottom but the top of the whole structure, and they can be replaced and discarded without damaging it" (11).

Outsiders, and I include the sociologist and philosopher among them, generally have no idea of what analytic data are. Never having undergone an analysis nor having pursued the rigorous training that would give them an opportunity to acquire data as an analyst, they remain necessarily uninformed. In a sense, the analyst's unique method of gathering data, the analytic sessionthat special circumstance that constitutes the wellspring of material on which psychoanalysis bases its findings, can be likened to microscopy. Just as the ignoranti who have never so much as seen a microscope condemned and ridiculed Leuwenhoek's descriptions of the marvelous organisms and structures he espied, so do similarly disposed individuals manufacture diatribes against analysis. The technique of free association-and this cannot be overemphasized-makes the analyst privy to a whole world of data unmet within ordinary circumstances, and generally inaccessible. Criticisms of psychoanalysis that pay no heed to this fact cannot be taken seriously.

Waelder (10) examines the so-called exact sciences, such as chemistry and physics (one should bear in mind that he himself had been a physicist before an analyst) and gleans four prerequisites for their exactitude:

1. Events must be contemporary, able to be repeated over and over, like the movements of the stars, or at will.

2. Variables must be loosely coupled so that it becomes possible to isolate the effect of one. When they are coupled closely, evidence for cause and effect becomes difficult to ascertain, for when one variable changes, by definition the others change simultaneously.

3. The subject under investigation must not change significantly during the course of the investigation, otherwise new unknowns are introduced.

4. The subjects under study must be sufficiently small so that what happens to individual units, e.g., a single electron, has little importance, since only the aggregate matters, thus rendering statistical management adequate and appropriate. 
Psychoanalysis obviously meets none of the above. Its subject-Man-is a complex composite of closely coupled variables, as indeed every organism is, which changes constantly and does not lend itself to statistical treatment in any meaningful way. It surely is an implicit and necessary virtue of analysis that the behavior of an individual unit, unlike the electrons in Bohr's model of the hydrogen atom, is of the utmost significance; indeed, one can measure the progress of civilization by its increasing regard for the individual. Note, however, that neither the biological nor social sciences meet these criteria. Evolution, certainly considered one of the most important scientific advances in the world's history, has very little "direct" evidence in its support. Its appeal lies in the fact that any other proposed interpretation of the data with which it concerns itself is far less satisfactory. Our belief that Columbus arrived in America in 1492 is similarly founded, to Waelder's example (10). The existing evidence is indirect and circumstantial, consisting of letters, scattered reports, and the like. No present day Methuselah can testify to his setting foot on shore, but this reconstruction of events fits such a mass of data from so many varied sources that the probability of coincidence is infinitesimal. Or to quote Stephen Jay Gould, "We know that the sun is hub to our little corner of the universe, and that ties of genealogy connect all living things on our planet, because these theories assemble and explain so much otherwise disparate and unrelated information ..." (12).

Thus psychoanalysis. Concepts that have evolved from the enormous mass of data derived from the analytic setting simply present the best fit.

With respect to Karl Popper's contention that analytic theories are not "falsifiable," it should be noted that throughout the history of psychoanalysis theories have continually been proposed, revised, and rejected, all in accordance with the scientific method that requires an honest accounting of the observed phenomena. To cite a specific example of the falsifiability of analytic theories, repression as the sine qua non of neurosis could be disproved simply by the presentation of a case in which all inner conflicts have never ceased to be fully accessible to consciousness and no repression of any aspect of them can be detected, to paraphrase Waelder (10) once again.

Eventually it seems that psychoanalytic theory might be confirmed or invalidated by the sort of direct, experimental evidence we associate with the "exact" sciences. However, attempts of this kind would require an exquisite mastery of analytic concepts as well as uncommon ingenuity to earn validity themselves. Until then we may be content to say of the method of psychoanalysis, like that of Zadig, "Nothing can be more hopelessly vulgar, more unlike the majestic development of a system of grandly unintelligible conclusions from sublimely inconceivable premises such as delights the magian heart" (13). And it may be that precisely in its "vulgar" preoccupation with the truth about man's dark impulses, in its ruthless disavowal of the fictions perpetrated by personal or organized religions, analysis has incited the heated but unfounded accusations that it is not truly a science. That members of the analytic profession should 
participate in the chorus might well be an indication of the powerful need for the comforts of Illusion within us all.

\section{REFERENCES}

1. Masson JM: The Assault on Truth. New York, Farrar, Straus and Girous, 1984

2. Cardinal M: The Words to Say It. Cambridge, Mass, VanVactor and Goodheart, 1983

3. Freud S: New introductory lectures on psychoanalysis. Standard Edition XXII:160, 1933

4. Freud S: New introductory lectures on psychoanalysis. Standard Edition XXII:156, 1933

5. Freud S: New introductory lectures on psychoanalysis. Standard Edition XXII:175, 1933

6. Freud S: New introductory lectures on psychoanalysis. Standard Edition XXII:174, 1933

7. Freud S: The questions of lay analysis. Standard Edition XX:254, 1926

8. Freud S: The questions of lay analysis. Standard Edition XX:252, 1926

9. Freud S: An autobiographical study. Standard Edition XX:56, 1925

10. Waelder R: Psychoanalysis, scientific method, and philosophy. J Am Psychoan As 10:617-637, 1962

11. Freud S: On narcissism: an introduction. Standard Edition XIV:77, 1914a

12. Gould SJ: Nasty little facts. Natural History 94(2):14, 1985

13. Huxley TH: On the method of Zadig, in Autobiography and Essays. Edited by Brander M. New York, Kraus Reprint Co, 52, 1969 